\title{
Background-oriented schlieren technique in experimental research regarding the effect of explosion pressure
}

\author{
Adrian Bogdan Șimon-Marinică ${ }^{1 *}$, Nicolae-Ioan Vlasin ${ }^{1}$, Florin Manea ${ }^{1}$, and Dorin \\ Popescu $^{2}$ \\ ${ }^{1}$ National Institute for Research \& Development in Mine Safety and Protection to Explosion - \\ INSEMEX Petroșani, 32-34 G-ral. V. Milea Street, Romania \\ ${ }^{2}$ University of Craiova, Faculty of Automatics, Computer Science and Electronics - ACEUCV \\ Craiova, Bulevardul Decebal 107, Craiova 200776, Romania
}

\begin{abstract}
In the following paper, experimental results regarding the effect of explosion pressure are obtained from open field experiments with detonation of explosive charges. In addition, sensors that can be used for security applications for the detection of toxic and explosive compounds, as well as mobile systems for the detection of shock waves due to explosions were used to acquire more detailed results. Sensors are the main components in products and systems used to detect chemicals and volatile organic compounds (VOCs) targeting applications in several fields, such as: industrial production and the automotive industry (detection of polluting gases from cars, medical applications, indoor air quality control. The sensory characteristics of a robot depend very much on its degree of autonomy, the applications for which it was designed and the type of work environment. The sensors can be divided into two categories: internal status sensors (sensors that provide information about the internal status of the mobile robot); external status sensors (sensors that provide information about the environment in which the robot operates). Another classification of these could be: distance sensors, position sensors, environmental sensors - sensors that provide information about various properties and characteristics of the environment (example: temperature, pressure, color, brightness), inertial sensors.
\end{abstract}

\section{Introduction}

This paper presents the use of gradient flow visualization technique, also known as Background Oriented Schlieren (BOS) over the shock wave in experimental study upon sensors that can be used for safe applications in society by detecting toxic and explosive compounds, as well as mobile systems for detecting shock waves due to explosions. Sensors are the main components in products and systems used to detect chemicals and volatile organic compounds that target applications in several fields, such as: industrial production

\footnotetext{
* Corresponding author: bogdan.simon@insemex.ro
} 
and the automotive industry (detection of polluting gases from cars), medical applications, indoor air quality control, etc. Some key requirements for sensors include selectivity, for example the detection of traces of concentrations of volatile organic compounds and chemical agents in the presence of airborne compounds such as water vapor, sensitivity, the minimum concentration of target gases that can be detected, response speed, reversibility, energy consumption. Commercial chemical sensors based on semiconductor metal oxides, namely tin dioxide $\left(\mathrm{SnO}_{2}\right)$, indium oxide $\left(\mathrm{In}_{2} \mathrm{O}_{3}\right)$, zinc oxide $(\mathrm{ZnO})$, etc. are the most common sensors. The principle of operation of these sensors is based on changes in resistance to volatile organic compounds exposure, for example oxidation reactions between volatile organic compounds and the oxide surface. Tin dioxide $\left(\mathrm{SnO}_{2}\right)$ is the most common active material used in sensors because it interacts with a wide range of gas molecules and has a strong change in electrical resistance. The main advantages of tin dioxide-based sensors are high sensitivity and low cost in production. However, due to the low electrical conductivity at room temperature, it is necessary for these sensors to be used at high temperatures. High temperatures, which lead to high power consumption, are the biggest disadvantages of these sensors. In the study on the mobile system for detecting shock waves due to explosions, the current techniques in the implementation of mobile robot movement were consulted, concepts, techniques, results that can be used, gaps and problems specific to mobile robots were identified that have not yet been investigated in the field. The sensory characteristics of a robot depends very much on its rank of autonomy, the applications for which it was designed and the type of working environment. The sensors can be divided into two categories, namely: internal status sensors (sensors that provide information about the internal status of the mobile robot), external status sensors (sensors that provide information about the environment in which the robot operates). Another classification of these could be: distance sensors, position sensors, environmental sensors - sensors that provide information about various properties and characteristics of the environment (example: temperature, pressure, color, brightness), inertial sensors. The central unit of the mobile robot can process the measurable qualitative / quantitative information delivered by the sensors, after a possible amplification, signal processing / conditioning, conversion, and can transmit it through the communication system to an operator or a computer system. Thus, pressure / hazardous / explosive gas sensors can be integrated either in the environment or in a mobile robot, so that the information provided by them can help to avoid the occurrence of special situations, emergencies, or in the case of explosion could provide information about the amplitude of the pressure due to the shock wave to which a victim was subjected.

\section{Image processing technique}

Background oriented schlieren is an optical measurement technique and it used for visualizing density gradients. The principle is the deviation of light rays that pass through a density gradient, which is well known from the Schlieren and Shadowgraph techniques [1]. The deviation is caused by the variation of the refractive index of the transparent media (air). The common steps of the method are imaging of a background through a flow of interest, and then software analysis that manipulates the data to find the density gradients. In its simplest form, BOS makes use of simple background patterns of the form of a randomly generated dot-pattern. The size of the pattern should ideally be optimized according to the magnification of the set-up. In the test presented in the paper, the background was a forest. The technique could probably be improved by using a random dot pattern, but would be impractical due to scale. The visualized shock front is not always visible along its entire contour, and present gap as shown in the figure below, figure 1. 


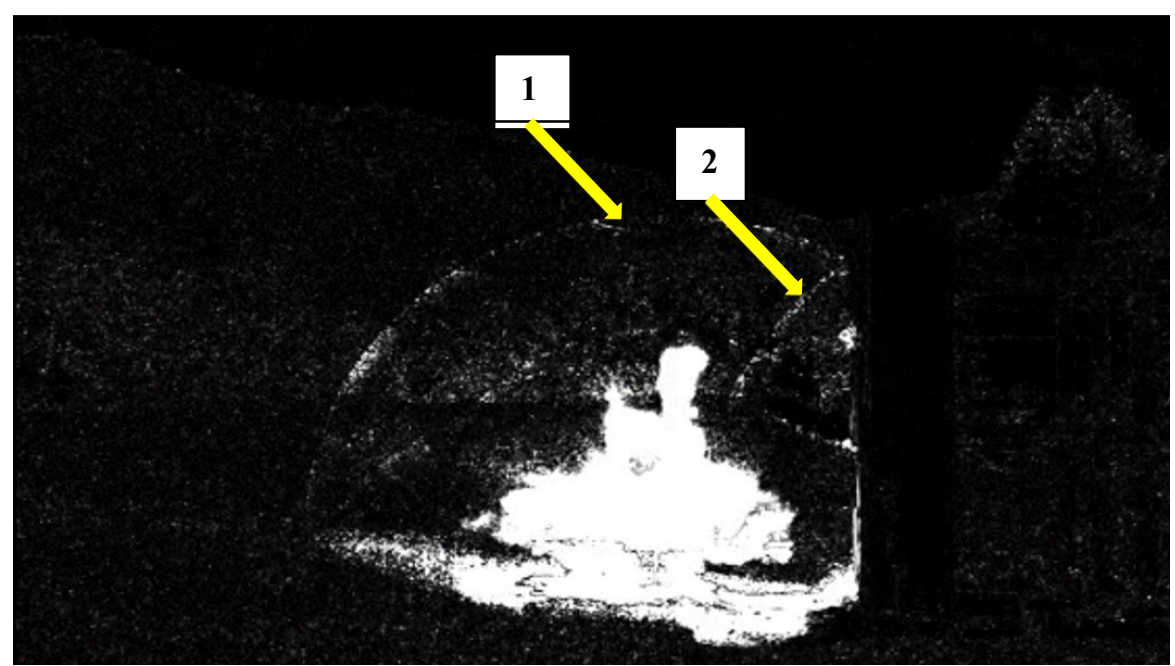

Fig. 1. Presence of gaps is shock wave propagation

1: Gaps 2: Reflected shock wave

These gaps are caused by the absence of background, as the shock front propagates lower than trees. The blast waves produced by sudden release of energy are normally characterized by a supersonic shock front followed by an exponential type decay of its physical properties. Unlike shock waves that attenuate as they expand spherically, the shock wave from an internal blast can change its propagation properties depending on the physical barriers.

\subsection{Background Oriented Schlieren (BOS) Methodology}

The principle of the technique is the refractive index variation due to density gradients in the flow. The determination of the density field using BOS thus involves the following steps: the calculation of displacements in the background which is imaged through the flow of interest, the calculation of the line-of-sight integrated density field by solution of the Poisson equation, which is the gradient of the above displacement, and the use of optical tomography (filtered back-projection) to determine the density field in the actual plane of interest. The background-oriented schlieren method is also based on the analysis of image displacements. However, the structures are a feature of the background that can be illuminated with incoherent light and imaged through a fluid containing spatial density gradients.

Since digital evaluation and white-light illumination (at least for surface deformation measurements) are also known in speckle interferometry, BOS could also be named whitelight speckle density photography. However, the name background oriented schlieren technique is the most common. name, as background oriented describes the fact that the camera used for the recording focuses onto objects behind the flow under investigation. Additionally, the term schlieren, most intuitively tells a fluid experimentalist that the technique quantifies the first spatial derivative of density, integrated along the path of light.

\section{Design of open field explosive tests for ballistic data collection}

An explosion [2] is defined by a very large amount of energy that is released in a short period of time. This release of energy can be done by pressure, temperature, radiation or even flying debris. At its origin an explosion can be physical or chemical by nature. The most common examples of physical explosion are lightning, steam pressure vessels and nuclear power. Gas or dust explosions can be divided into two groups: deflagration and detonation. In order to 
determine how to affect the internal structure and impurity of various materials used in the experimental study on sensors that can be used for safe applications in society by detecting toxic and explosive compounds, as well as mobile systems for detecting shock waves due to explosions, by the reaction products and by the thermal / dynamic effects generated by the detonation of the various categories of explosive materials, the following test program is designed:

a.) Selecting the category of target material, establishing the shape, weight and fastening devices and mounting the target on the area within the Test Site;

b.) The selection of the category of explosive materials, the determination of its mass, the shape of the detonating charge and the disposition towards the target, as well as the distance from it;

c.) Carrying out the detonating explosive charge and establishing the location of the target;

d.) Preparation of the explosive charge igniter, in the two variants: detonating electric igniter, respectively non-electric detonating igniter;

e.) Making the connection between the igniter and the initiating device, in the two variants: electric shooting cable, respectively shock tube;

f.) Withdrawal of personnel from the test area, in the observation post;

g.) Acoustic and visual alarm prior to the fire command;

h.) Initiation of the igniter of the explosive charge by the professional pyrotechnic personnel by actuating the initiating device (explosive, either for detonating electrical igniter or for non-electric detonating igniter);

i.) Detonation of the explosive charge;

j.) Dissipation of gases generated by detonated explosive materials;

k.) Ensuring the security of access to the plateau area by the professional pyrotechnic personnel (observation of the complete detonation of explosives);

1.) Sampling of the residues of the target materials, in order to directly ascertainment (thermal and dynamic effects), the subsequent analysis in the laboratory of the degree of damage to the structure and the establishment of the impregnation with reaction products characteristic of the type of detonated explosive.

The basic scheme of the experimental field test is shown in figure 2 .
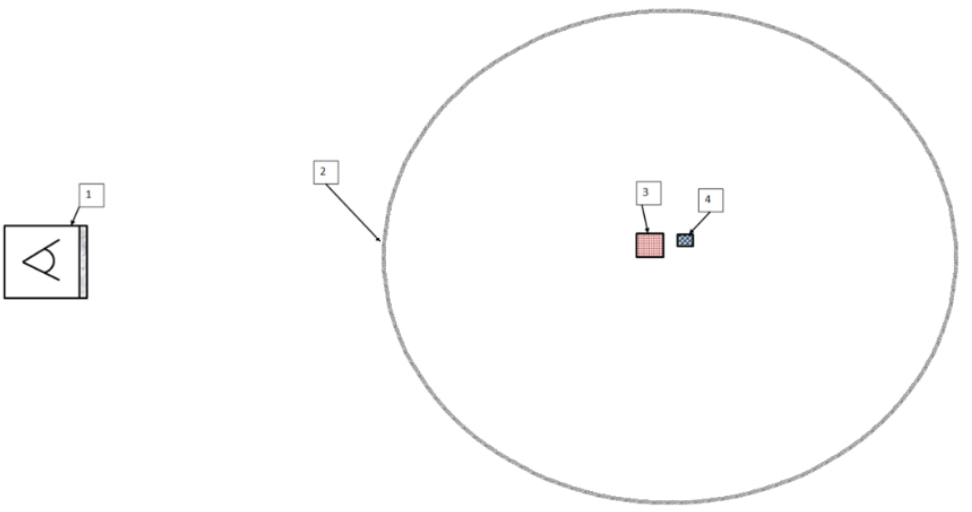

1. Observation post

3. Target (material used for test)

2. Open field zone

4. Explosive charge

Fig. 2. Basic setup for open field explosive test in order to collect ballistic data 


\subsection{Technical characteristics of explosive materials}

This paper subsection exemplifies the technical characteristics of explosive materials that could be used in further research:

a.) Dynamite. Explosive based on nitroglycerin / nitroglycol cartridge with $\phi 25 \mathrm{~mm}$ wrapped in white paraffin paper, weighing $100 \mathrm{~g}$ and $200 \mathrm{~g}$;

b.) Explosive gel. Explosive consisting of saturated aqueous solutions of ammonium nitrate in order to increase the charge density, respectively to increase the volumetric energy of explosion;

c.) TNT (trotyl). Explosive in the form of a yellowish crystalline powder with the chemical formula $\mathrm{C}_{7} \mathrm{H}_{5}\left(\mathrm{NO}_{2}\right)_{3}$, used in powder, pressed or in cast form and in granular form;

d.) Hexogen-based busters. Explosives used for initiating of simple explosive charges or explosive gels containing hexotols (mixture of TNT and phlegmatized or nonphlegmatized hexogen) as a pouring mixture;

e.) Detonating electrical igniters: These are initiation devices provided with electrical components that ensure the transformation of electrical energy into thermal energy. These can be: depending on the ignition and detonation duration (instantaneous igniters, normal delay igniters (long delays) and igniters with a millisecond delay); depending on the ignition mode (igniters with incandescent wire or bridge, electric spring igniters, igniters with a very good conductive substance); by sensitivity (low intensity igniters $(0.8-1.0 \mathrm{~A})$; medium intensity igniters $(1.5-1.7 \mathrm{~A})$; high intensity igniters (25A); environmental safety), igniters for explosive environments, heat resistant igniters, igniters resistant to hydrostatic pressures);

f.) Non-electric detonating igniters: These are igniters or mini detonators that are initiated due to the strong flame that propagates through the shock tube (Nonel tube) and reaches the load in the igniter. These can be: Nonel LP type (produced in 15 delay stages with the interval between 2 successive stages of 100-500 milliseconds and the total interval of 2500-6000 milliseconds, with the standard length of the Nonel tube of $6 \mathrm{~m}$, having the limits of variation between 3.0-9.0 m); type Nonel MS (produced in 18 delay stages with the interval between 2 successive stages of 25 milliseconds, with the standard length of the Nonel tube of $6 \mathrm{~m}$, with variation limits between 2.4-96.0 m); Nonel UNIDET type (are produced in a range of 5 types with a delay interval of 25 milliseconds starting from 400 milliseconds with the standard length of the Nonel tube of $6 \mathrm{~m}$, with variation limits between 2,4-96,0 $\mathrm{m}$ ).

\section{BOS technique to study the effect of explosive pressure from detonation of explosive charges over pressure sensors and mobile platform}

In order to carry out research on the propagation of the pressure wave when detonating explosive charges [3], on the pressure sensors and the mobile platform with pressure sensor, an experimental assembly was performed as follows and detailed in figure 3 :

a.) A flat open ground surface was selected, without obstacles;

b.) The mobile platform with pressure sensor was placed at a distance of $5 \mathrm{~m}$ from the explosion;

c.) 4 pressure sensors were mounted in cascade (two explosion pressure measurement systems were used, so that cylindrical sensors were placed on the bayonet sensors, both systems using Integrated Electronics Piezo Sensors Electric IEPE) at the following distances from the explosive charge: 
- Pressure sensor PS1 at 3m;

- Pressure sensor PS2 at 5m;

- Pressure sensor PS3 at 7m;

- Pressure sensor PS4 at 9m;

d.) Metal support for suspending the explosive charge;

e.) The following type of RIOMAX explosive charge was used, with the following quantities: 143g, 286g, 429g, 572g (RIOMAX cartridges).

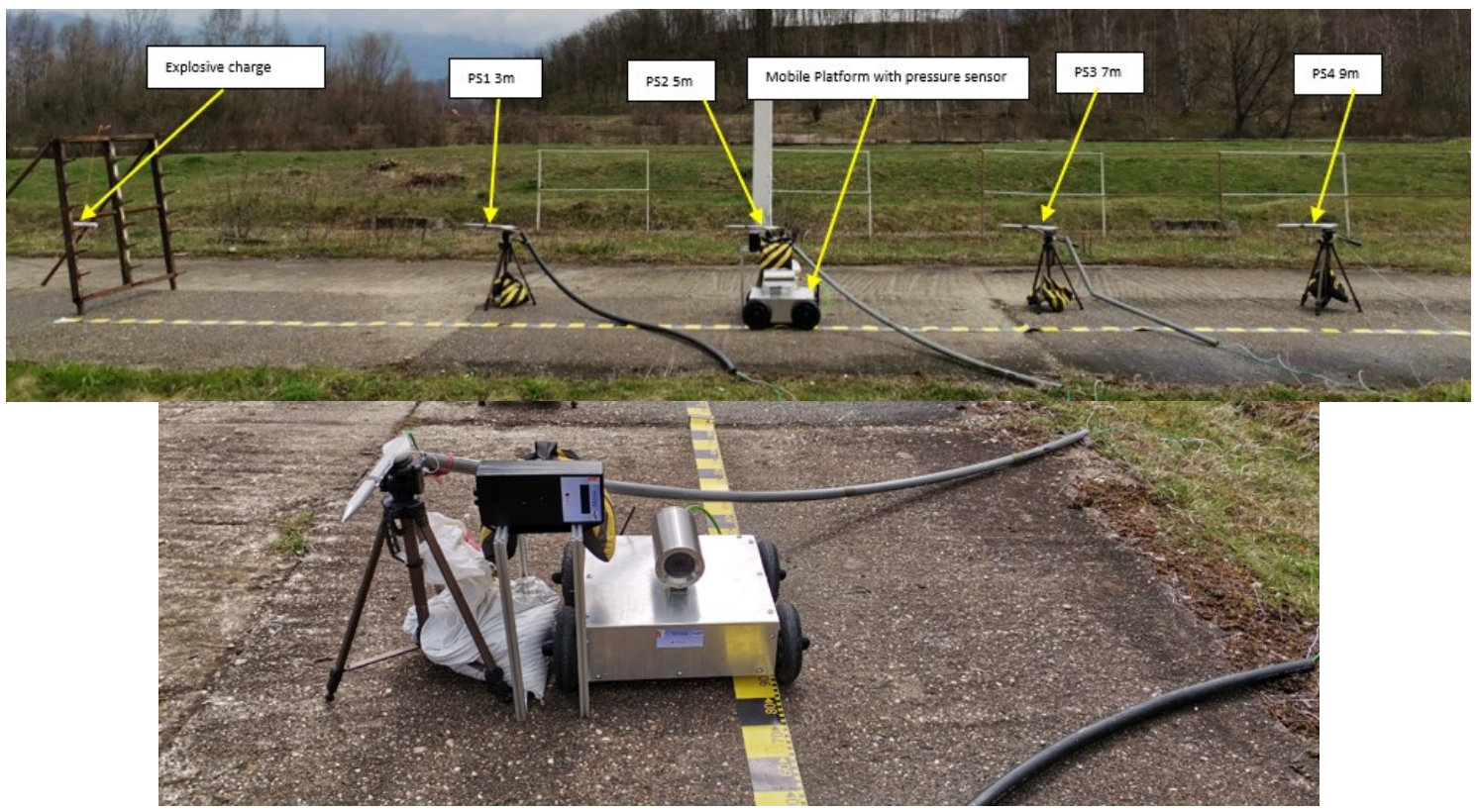

Fig. 3. In line setup for pressure sensors and mobile platform with pressure sensor

The results of the pressure curve sensors for each distance and for each type of explosive are presented in the table below, table. 1:

Table 1. Results from the sensors that recorded the pressure curves.

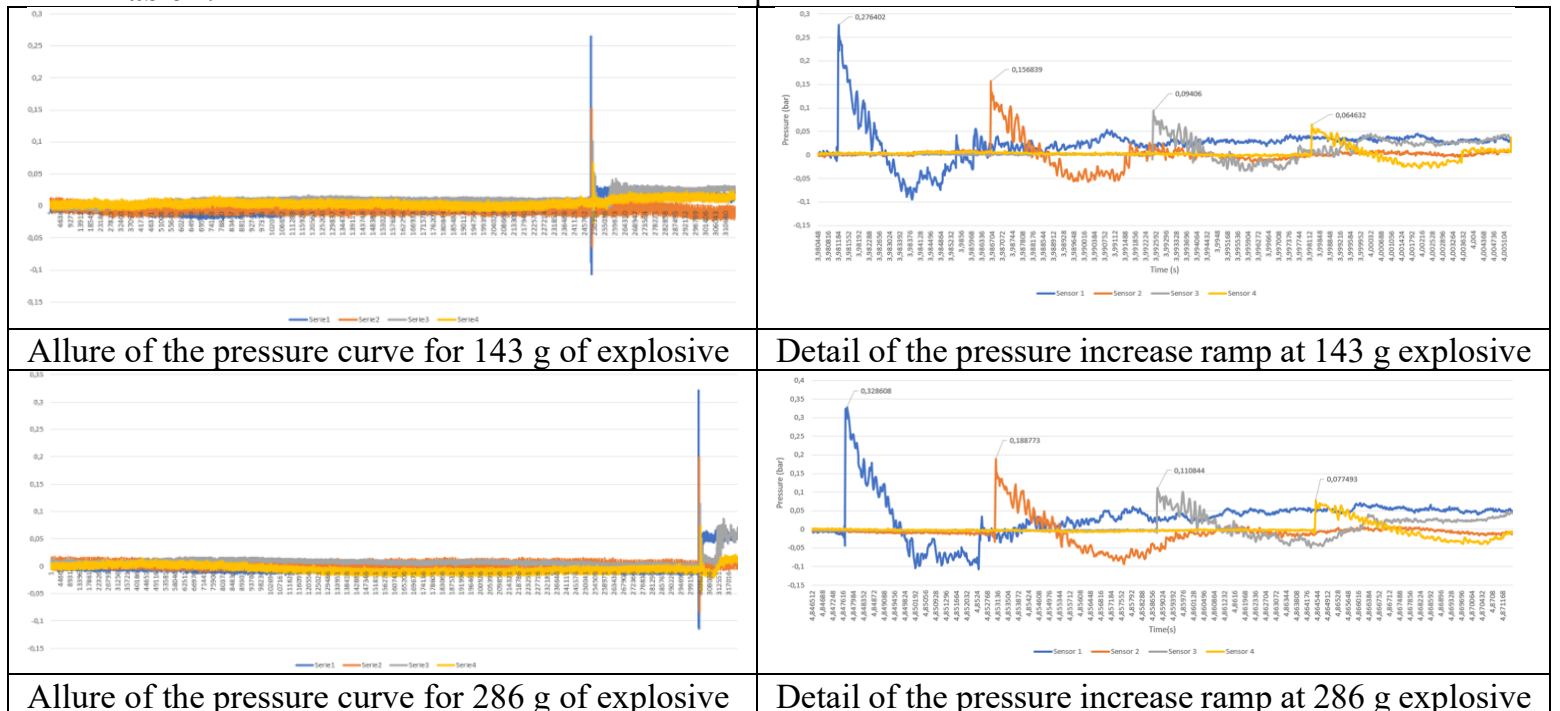




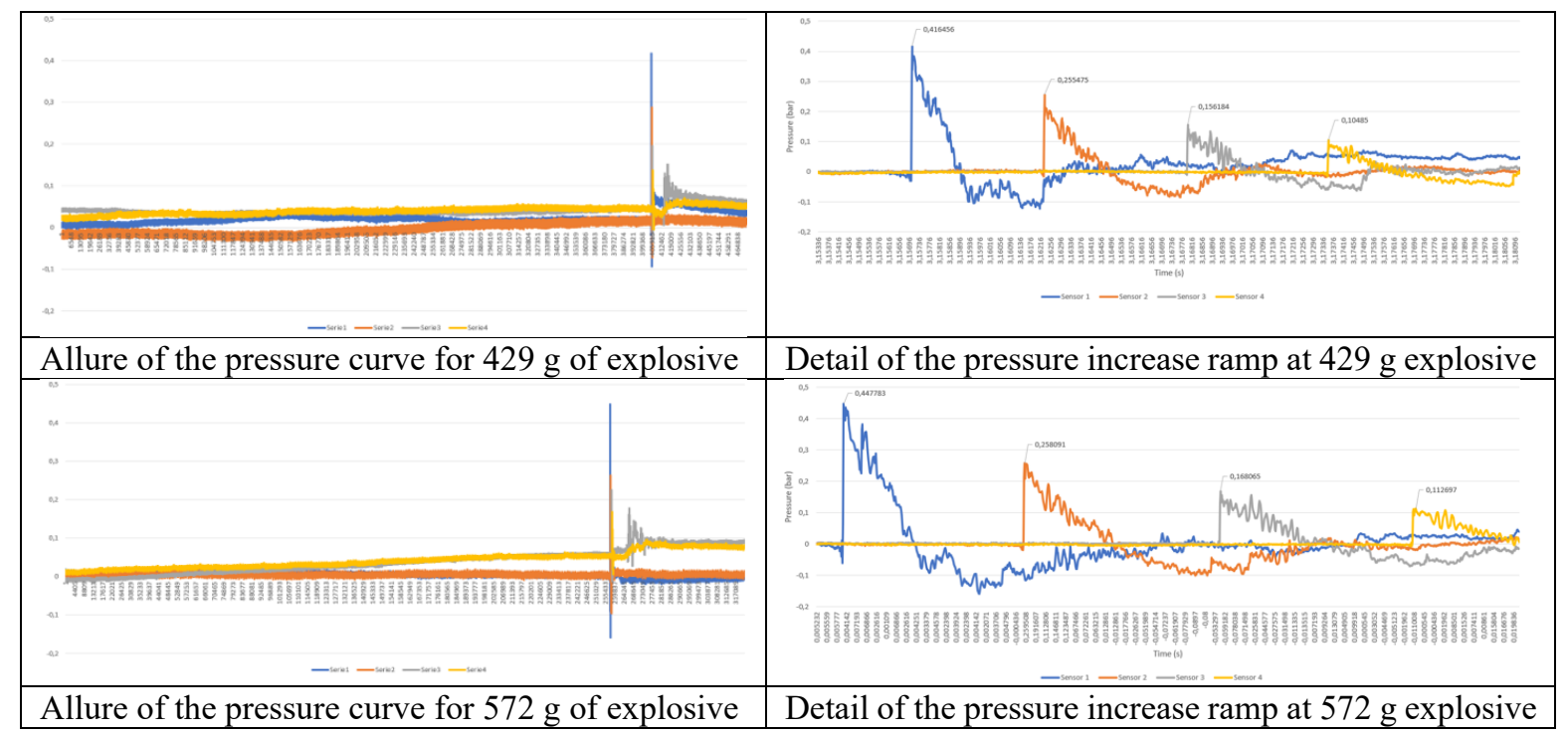

\subsection{Processing high speed images from explosive tests with BOS technique}

The visualization of the air pressure wave for the experiment with $143 \mathrm{~g}$ explosive is shown in figure 4, the undistorted circular contour next to the pressure sensors is observed) by using the BOS effect (Background Oriented Schlieren), applied on fast video filming with 8300 frames per second and resolution of $1280 \times 720$ pixels.
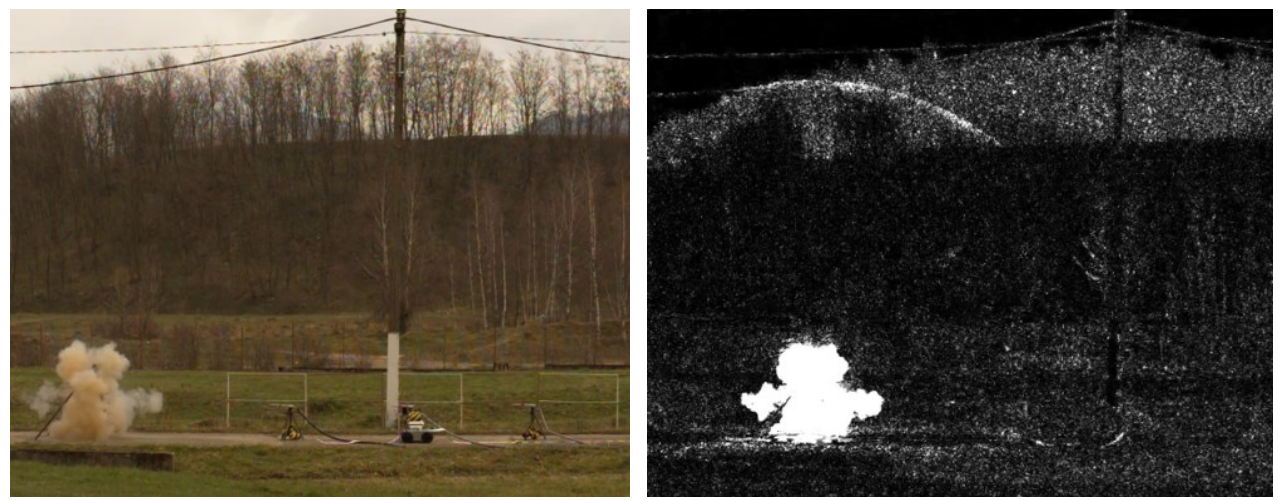

Fig. 4. Detonation of $143 \mathrm{~g}$ explosive charge

For the air pressure wave related to the experiment with $268 \mathrm{~g}$ explosive, the visualization of the pressure wave is rendered using the BOS technique in figure 5. 

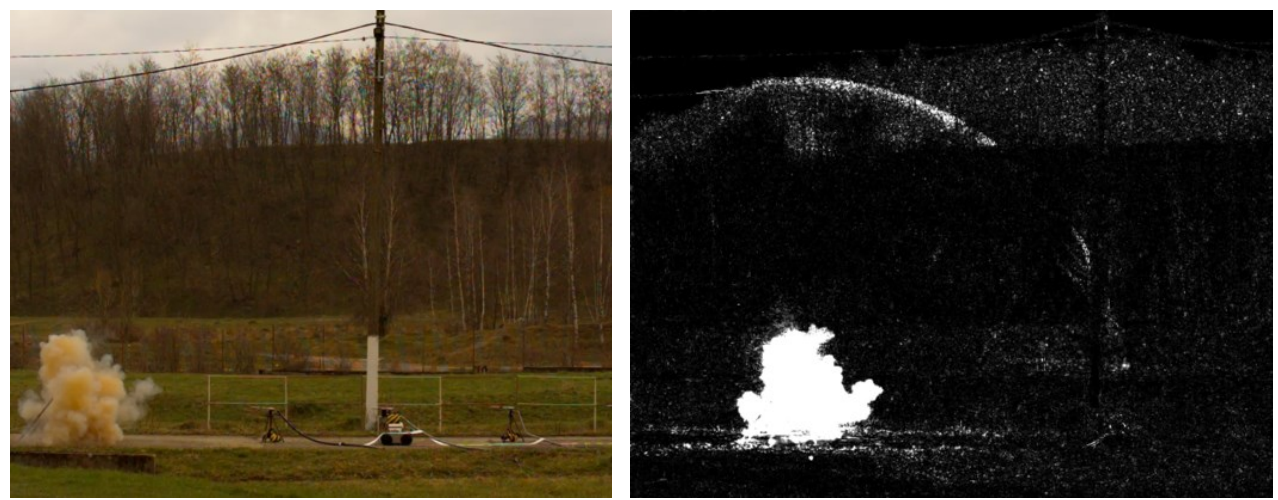

Fig. 5. Detonation of $286 \mathrm{~g}$ explosive charge

For the air pressure wave related to the experiment with $429 \mathrm{~g}$ explosive, the visualization of the pressure wave is rendered using the BOS technique in figure 6.
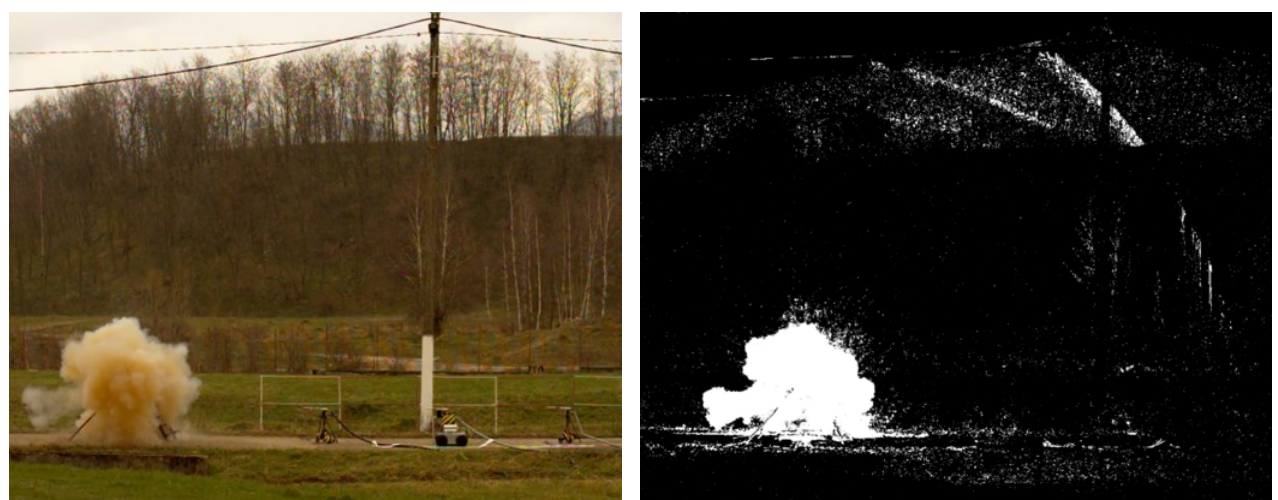

Fig. 6. Detonation of $429 \mathrm{~g}$ explosive charge

For the air pressure wave related to the experiment with $572 \mathrm{~g}$ explosive, the visualization of the pressure wave is rendered using the BOS technique in figure 7.
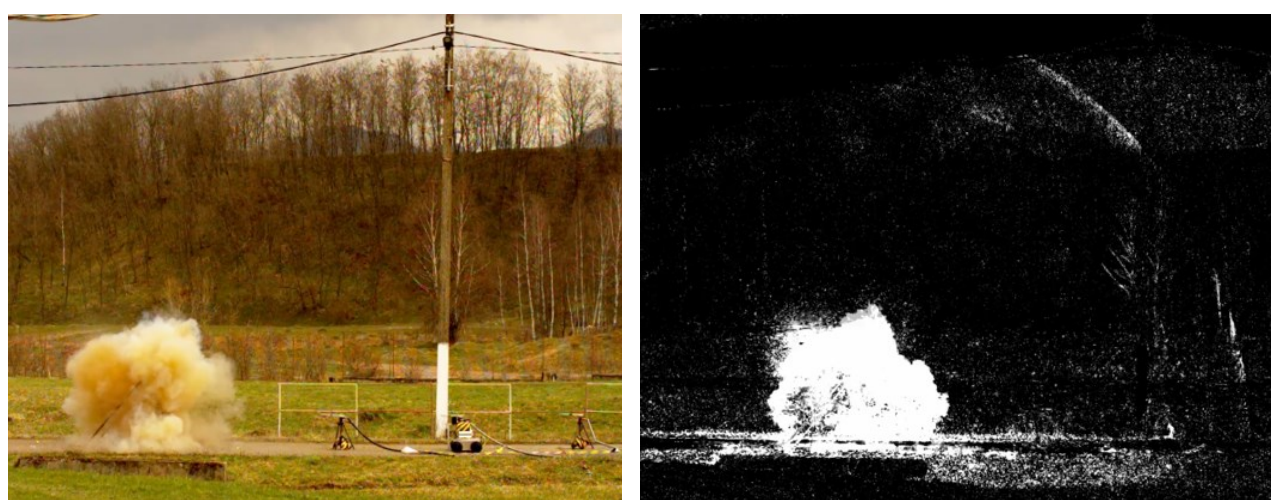

Fig. 7. Detonation of $572 \mathrm{~g}$ explosive charge 


\section{Conclusions}

Presently, BOS is frequently used as an easy-to-use visualization of flows having density gradients due to varying temperature or pressure. Its strength lies in the simplicity of a basic setup, and this allows for its application in experimental environments which are unsuited for other measurement techniques [4]. This advantage has further been developed to a state where BOS can be used for a large number of investigations in various fields. Due to new camera designs and the rapid development in the area of digital imaging and image processing, higher signal-to-noise ratios and increased resolution counteract the main disadvantage of the BOS, which is the limited resolution inherent with the statistical displacement computation.

\section{Acknowledgements}

This paper was developed within the Nucleu-Programme, carried out with the support of Romanian Ministry of Research, Innovation, and Digitization project no. PN-19-21-01-05, project title: Fundamental research and computer simulations on the initiation of explosive gas mixtures by potential sources of ignition of a different nature (in Romanian: Cercetări fundamentale și simulări computerizate privind inițierea amestecurilor gazoase explozive prin surse potențiale de aprindere de natură diferită).

\section{References}

1. A.B. Șimon-Marinică, E. Ghicioi, N. I. Vlasin, M. C. Șuvar, G. D. Florea, Visualization and record methods for the initiation of air-methane explosive atmospheres, The 19th International Multidisciplinary Scientific Geo Conference - SGEM 2019 Conference Proceedings, 1165- 1171 (2019);

2. Vlasin N., Ghicioi E., Florea D., Vass Z., Chiuzan E., Researches regarding gas explosions by combined imagistic methods, Proceedings of the 18th International Multidisciplinary Scientific GeoConference SGEM 2018, Bulgaria, Vol. 18, pp 777-783, 2018;

3. A.B. Șimon-Marinică, G. D. Florea., Vass Z., Muntean L. Babut A., Infrared scanning method for long distance identification and visualization of gases, Proceedings of the 20th International Multidisciplinary Scientific GeoConference SGEM 2020, Bulgaria, Vol. 20, pp 25-32, 2020;

4. G.S. Settles, Schlieren and Shadowgraph Techniques, Springer-Verlag Berlin Heidelberg, 2001 